\title{
Mesoporous Adsorbents for Desulfurization of Model Diesel Fuel: Optimization, Kinetic, and Thermodynamic Studies
}

\author{
Anakaren Botana-de la Cruz ${ }^{1}$, Philip E. Boahene ${ }^{1}$, Sundaramurthy Vedachalam ${ }^{1}$, \\ Ajay K. Dalai ${ }^{1, *}$ and John Adjaye ${ }^{2}$ \\ 1 Catalysis and Chemical Reaction Engineering Laboratories, Department of Chemical and Biological \\ Engineering, University of Saskatchewan, Saskatoon, SK S7N 5A9, Canada; \\ anakaren.botana@usask.ca (A.B.-d.l.C.); peb225@mail.usask.ca (P.E.B.); suv549@mail.usask.ca (S.V.) \\ 2 Syncrude Edmonton Research Centre, Edmonton, AB T6N 1H4, Canada; Adjaye.John@syncrude.com \\ * Correspondence: ajay.dalai@usask.ca
}

Received: 14 October 2020; Accepted: 13 November 2020; Published: 14 November 2020

\begin{abstract}
Mesoporous alumina-based adsorbents consisting of a $\pi$-electron acceptor complexing agent (2,7-dinitro-9-fluorenone) were synthesized and characterized. Adsorbents were screened for the removal of sulfur compounds from a model ultra-low-sulfur diesel fuel via a charge transfer complex (CTC) mechanism. The sulfur adsorption isotherms and kinetics were examined. The kinetics of sulfur adsorption followed a pseudo-second-order model with the CTC adsorbents. Among the three adsorbents screened, a commercial $\gamma-\mathrm{Al}_{2} \mathrm{O}_{3} \mathrm{CTC}$ adsorbent showed the highest desulfurization in a short-run period. The regeneration of spent adsorbent was studied with three different polar solvents, namely chloroform, dichloromethane, and carbon tetrachloride. Dichloromethane was found to be the most suitable solvent for extracting a major portion of sulfur compounds occupied in the pores of the spent adsorbent. $\gamma-\mathrm{Al}_{2} \mathrm{O}_{3} \mathrm{CTC}$ adsorbent can be reused after regeneration. Thermodynamic parameters such as $E_{a}, \Delta G, \Delta H$, and $\Delta S$ provided a better insight into the adsorption process.
\end{abstract}

Keywords: mesoporous adsorbent; desulfurization; charge transfer complex; adsorption; kinetics and thermodynamics

\section{Introduction}

The world's population has exponentially increased over the last few decades with a corresponding increase in demand for different resources, including fossil fuel. Over the last two decades, fossil fuel consumption has increased worldwide due to fast-growing economies. The burning of fossil fuel causes air pollution, which has been of great global concern, as it becomes a precursor for many health and environmental problems. Emissions of air pollutants, such as sulfur oxides, nitrogen oxides, carbon monoxide, particulate matter, and volatile organic compounds, come from various sources, notably among them is the combustion of fuels in internal combustion engines. To control these emissions, governments around the world have established certain limits on the allowable concentration of certain compounds in fuels that are being used for transportation. Particularly, sulfur compounds present in fossil fuels have a major impact on the environment when they are not under regulations. Oil refineries usually employ hydrotreatment to reduce the amounts of sulfur, nitrogen, oxygen, aromatics present in fuels. Since the removal of refractory sulfur compounds beyond certain thresholds through the conventional hydrotreating process is still challenging, several alternative methods have been studied to reduce levels of the recalcitrant species in fuels [1-6].

Among the alternative methods, adsorptive desulfurization (ADS) has the attention of many researchers around the world since it is a very promising and cost-effective route [7-11]. Unlike 
hydrotreating, ADS is a low-temperature process and does not require costly hydrogen gas [12]. The adsorptive desulfurization process can be physical or chemical. The physical adsorption pathway does not involve the formation of any new compounds, rather it results from van der Waals forces leading to mild attractions between molecules of sulfur compounds (adsorbate) and an adsorbent [13]. In the chemical adsorption route, the adsorbate-adsorbent interaction involves chemical reactions resulting from the sharing of electrons. The key factors influencing adsorptive desulfurization are the textural properties (large surface area, pore size, and pore volume) of the adsorbents and their affinity towards organic nitrogen compounds. Recently, we have reported 2,7-Dinitro-9-fluorenone (DNF) functionalized mesoporous $\mathrm{Al}_{2} \mathrm{O}_{3}$, Ti-substituted mesoporous $\mathrm{Al}_{2} \mathrm{O}_{3}$, and commercial $\gamma-\mathrm{Al}_{2} \mathrm{O}_{3}$ mesoporous alumina for desulfurization of liquid fuels [14]. For an adsorbent to be considered feasible for commercial and industrial applications, several investigations, including process parameters optimization, kinetic evaluations, as well as thermodynamics, need to be studied. The objective of this study is to investigate the optimum sulfur adsorption conditions of mesoporous charge-transfer complex (CTC) adsorbents and test their regeneration and reusability. Besides, the kinetic and thermodynamic behaviors were also investigated to elucidate their possible adsorptive desulfurization mechanisms.

\section{Experimental}

\subsection{Materials and Chemicals}

Poly (ethylene oxide)-block poly (propylene oxide)-block poly (ethylene oxide) (P123), carbon tetrachloride $\left(\mathrm{CCl}_{4}\right)$ and dichloromethane were sourced from Sigma Aldrich (Oakville, ON, Canada). ACS grade nitric acid, methanol, toluene, and acetic acid were obtained from Fisher Chemical, Saskatoon, Canada. 2,7-Dinitro-9-fluorenone was sourced from the Tokyo chemical industry. Aluminum isopropoxide and ethylenediamine with purities of 98 and 99\%, respectively, were supplied from Alfa Aesar, Canada. ACS grade titanium (IV) isopropoxide and hydrochloric acid (37\% solution in water) were purchased from Acros Organics, Canada. Ethanol (anhydrous) was obtained from the Commercial Alcohols, Canada.

\subsection{Preparation of Adsorbents}

The synthesis method of the charge transfer adsorbents used in this study was described in detail in our previous publication [14]. In brief, the mesoporous $\mathrm{Al}_{2} \mathrm{O}_{3}$, titanium substituted mesoporous $\mathrm{Al}_{2} \mathrm{O}_{3}$ and commercial $\gamma-\mathrm{Al}_{2} \mathrm{O}_{3}$ were used as supports for the preparation of adsorbents $\mathrm{A}, \mathrm{B}$, and $\mathrm{C}$, respectively. The syntheses of adsorbents involved (i) preparation of supports, (ii) anchoring of a linker, ethylenediamine on supports, and (iii) immobilization of a $\pi$-acceptor, 2,7-dinitro-9-fluorenone on supports.

\subsubsection{Synthesis of Mesoporous $\mathrm{Al}_{2} \mathrm{O}_{3}$ and Titanium Substituted Mesoporous $\mathrm{Al}_{2} \mathrm{O}_{3}$ Supports}

The mesoporous $\mathrm{Al}_{2} \mathrm{O}_{3}$ support was synthesized by a sol-gel technique. Solution A was prepared by dissolving aluminum isopropoxide and titanium isopropoxide in ethanol under mechanical agitation. Similarly, solution B was prepared by dissolving P123 in ethanol. A sol-gel solution was prepared by mixing solutions $\mathrm{A}$ and $\mathrm{B}$. The resulting sol-gel solution was aged at $65^{\circ} \mathrm{C}$ for $108 \mathrm{~h}$ before calcination at $600{ }^{\circ} \mathrm{C}$ for $5 \mathrm{~h}$.

\subsubsection{Functionalization of Supports with Ethylenediamine}

Ethylenediamine (EDA) was used as a linker to anchor the $\pi$-acceptor on supports. EDA was immobilized on supports by mixing a methanol solution of EDA and the support. The resulting mixture was filtered, washed with methanol, and dried at $70{ }^{\circ} \mathrm{C}$ for $6 \mathrm{~h}$ in a vacuum oven. 


\subsubsection{Incorporation of $\pi$-Acceptor on Supports}

DNF $\pi$-acceptor was dissolved in toluene and acetic acid solution by mechanical mixing. To this, ethylenediamine functionalized support was added and refluxed for three days. The $\pi$-acceptor loaded adsorbent was filtered and washed with toluene. Finally, the material was dried under vacuum prior to characterizations and adsorptive studies using a model ultra-low-sulfur diesel fuel.

\subsection{Process Parameter Optimization}

To investigate the influence of process parameters and their combined interactions on the adsorptive desulfurization process, a set of experiments was designed by varying process parameters, such as temperature and time, as well as the adsorbent loadings. The model feed concentration was kept constant. Experiments were designed by the Central Composite Design (CCD) approach using the Design Expert ${ }^{\circledR}$ software (version 6.0.11, State-Ease Inc., Minneapolis, MN, USA). Table 1 shows the ranges of variables for the experimental design. As given in Table 2, a set of 19 experiments (14 unique) was designed, with the center point experiment replicated five times. Experiments were repeated to check reproducibility under the same set of conditions. The model feed used in this study contained $541 \mathrm{ppm}$ of sulfur, which was prepared by dissolving thiophene in ultra-low sulfur diesel (ULSD). Sulfur compounds mainly existing in diesel fuel are thiophene, benzothiophene (BT), dibenzothiophene (DBT). The CTC adsorbent used in this study removes organosulfur compounds through the $\pi$-complexation mechanism. The removal mechanism is the same for thiophene, benzothiophene, and dibenzothiophene and thus similar adsorption result is expected with all three organosulfur compounds. Besides, like thiophene, no internal diffusional barriers to benzothiophene and dibenzothiophene are expected since pores of CTC adsorbents are mesopores with diameters between 6 and $8 \mathrm{~nm}$ [14]. The typical adsorption experiment was carried out with $0.5 \mathrm{~g}$ of the adsorbent and $2.5 \mathrm{~g}$ of the model feed in a batch set up at required process conditions. The adsorbent was separated by filtration and the liquid product was analyzed with an Antek N/S analyzer for the total sulfur content.

Table 1. Optimization parameters and their corresponding range for the central composite design.

\begin{tabular}{cccc}
\hline Variables & Symbol & \multicolumn{2}{c}{ Range } \\
\hline Temperature $\left({ }^{\circ} \mathrm{C}\right)$ & $\mathrm{A} 1$ & 22 & 60 \\
Time $($ min) & $\mathrm{B} 1$ & 15 & 60 \\
Adsorbent loading $(\mathrm{g})$ & $\mathrm{C} 1$ & 0.25 & 0.75 \\
\hline
\end{tabular}

Table 2. Design of experiments for adsorption of sulfur.

\begin{tabular}{cccc}
\hline Run Number & Adsorbent Loading $(\mathrm{g})$ & Temperature $\left({ }^{\circ} \mathbf{C}\right)$ & Time $(\mathbf{m i n})$ \\
\hline 1 & 0.75 & & 60 \\
2 & 0.75 & 22 & 27 \\
3 & 0.25 & & 60 \\
4 & 0.25 & & 27 \\
\hline 5 & 0.75 & 60 & 60 \\
6 & 0.75 & & 27 \\
7 & 0.25 & & 60 \\
8 & 0.25 & & 27 \\
9 & 0.5 & & 43 \\
10 & 0.5 & & 43 \\
11 & 0.5 & 41 & 71 \\
12 & 0.5 & & 43 \\
13 & 0.5 & & 43 \\
14 & 0.5 & & 43 \\
15 & 0.5 & & 43 \\
16 & 0.5 & 73 & 43 \\
17 & 0.92 & & 43 \\
18 & 0.08 & & 43 \\
\hline 19 & 0.5 & &
\end{tabular}




\subsection{Adsorption Kinetics}

Kinetic studies were conducted in a stirred batch system consisting of a $15 \mathrm{~mL}$ glass vial in which a mixture of the adsorbent and the model feed was stirred at $400 \mathrm{rpm}$. The adsorbent to feed ratio was maintained at 1:5. To determine the minimum time required for the adsorbent to reach adsorption equilibrium, the experiments were carried out at different times ranging from $15 \mathrm{~min}$ to $72 \mathrm{~h}$. To investigate the adsorption mechanism, the temperature was kept constant at $22^{\circ} \mathrm{C}$.

After the duration for adsorption was elapsed, the adsorbent was recovered under vacuum and the treated oil product was collected and stored in vials for total sulfur and nitrogen analysis. Following the N/S analysis, the adsorption efficiency was calculated using the formula shown below:

$$
\mathrm{S} \text { removal efficiency }(\%)=\frac{\mathrm{S} \text { in the feed }(\mathrm{ppm})-\mathrm{S} \text { in the product liquid }}{\mathrm{S} \text { in the feed }(\mathrm{ppm})} \times 100
$$

The equilibrium adsorption capacities were calculated using the following formula:

$$
\mathrm{q}_{\mathrm{e}}=\frac{\mathrm{C}_{0}-\mathrm{C}_{\mathrm{e}}}{\mathrm{m}} \mathrm{V}
$$

where $C_{0}$ and $C_{e}$ are the initial and equilibrium concentrations of sulfur $\left(\mathrm{mg} \cdot \mathrm{L}^{-1}\right)$, respectively, $V$ is the volume of the feed used (L), and $\mathrm{m}$ is the mass of the adsorbent $(\mathrm{g})$.

\subsection{Adsorption Thermodynamics}

Using the reaction rate constant of the pseudo-second-order model, the activation energies of ADS on three adsorbents were calculated following a method reported by Laidler [15]. Using the Arrhenius equation, the activation energy, $\mathrm{E}_{2}$, was calculated as shown below:

$$
\ln \mathrm{E}_{2}=-\frac{\mathrm{E}_{\mathrm{a}}}{\mathrm{RT}}+\ln \mathrm{A}
$$

Moreover, using the data obtained from the adsorption experiments, the free activation energy $\left(\Delta \mathrm{G}^{0}\right)$ was determined by assuming that the adsorption process happened spontaneously. The changes in enthalpy $\left(\Delta \mathrm{H}_{0}\right)$ and entropy $\left(\Delta \mathrm{S}_{0}\right)$ were also calculated using the equations shown below:

$$
\begin{aligned}
\Delta G^{0} & =-R T \ln K_{D} \\
\Delta G^{0} & =-R T \ln K_{D} \\
\ln K_{D} & =\frac{\Delta S^{0}}{R}-\frac{\Delta H^{0}}{R T}
\end{aligned}
$$

where $\Delta \mathrm{G}^{0}\left(\mathrm{~kJ} \cdot \mathrm{mol}^{-1}\right)$ was calculated using the Van't Hoff equation, $\mathrm{R}$ is the universal gas constant, $8.314 \mathrm{~J} \mathrm{~mol}^{-1}$, $\mathrm{T}$ is the absolute adsorption temperature in $\mathrm{K}, \mathrm{K}_{\mathrm{D}}$ is the adsorption equilibrium constant. Using the slope and intercept of the plot $\left(\ln \mathrm{K}_{\mathrm{D}}\right.$ vs. $\left.1 / \mathrm{T}\right), \Delta \mathrm{H}^{0}$ and $\Delta \mathrm{S}^{0}$ were calculated.

\subsection{Regeneration and Reusability Studies}

The reusability study of the best adsorbent (adsorbent $C$ ) was carried out at the optimum process conditions (adsorbent loading $=30 \%$, time $=27 \mathrm{~min}$, temperature $=22{ }^{\circ} \mathrm{C}$, and $400 \mathrm{rpm}$ ), which were identified from the screening study. After the $24 \mathrm{~h}$ adsorption reaction, the adsorbent was regenerated with three different solvents, namely chloroform, dichloromethane, and carbon tetrachloride, using a Soxhlet extraction set-up. Chlorinated solvents have been reported in the literature to eliminate and dissolve oil-based and organic substances [16-18]. The spent adsorbent was placed inside the soxhlet apparatus in a cellulose thimble and extracted with $150 \mathrm{~mL}$ of solvent. During the Soxhlet extraction, the solvent was placed in a $250 \mathrm{~mL}$ round-bottom flask connected to a reflux condenser in an immersed 
heated oil bath maintained at the boiling point of each solvent. The extraction was carried out for $8 \mathrm{~h}$, and then adsorbent was dried and tested for reusability.

\section{Result and Discussion}

\subsection{Adsorption Parameters Optimization}

The CTC adsorbents used in this study were comprehensively characterized using BET, FTIR, $\mathrm{XRD}$, TGA, and XPS techniques. The results of characterization were reported in our previous publication [14]. These adsorbents belong to the category of charge-transfer complex (CTC) adsorbent. As given in Figure 1, they adsorb organosulfur compounds selectively through the $\pi$-complexation mechanism, which involves interactions between the $\pi$ orbitals of organic sulfur compounds and 2,7-Dinitro-9-fluorenone (DNF).

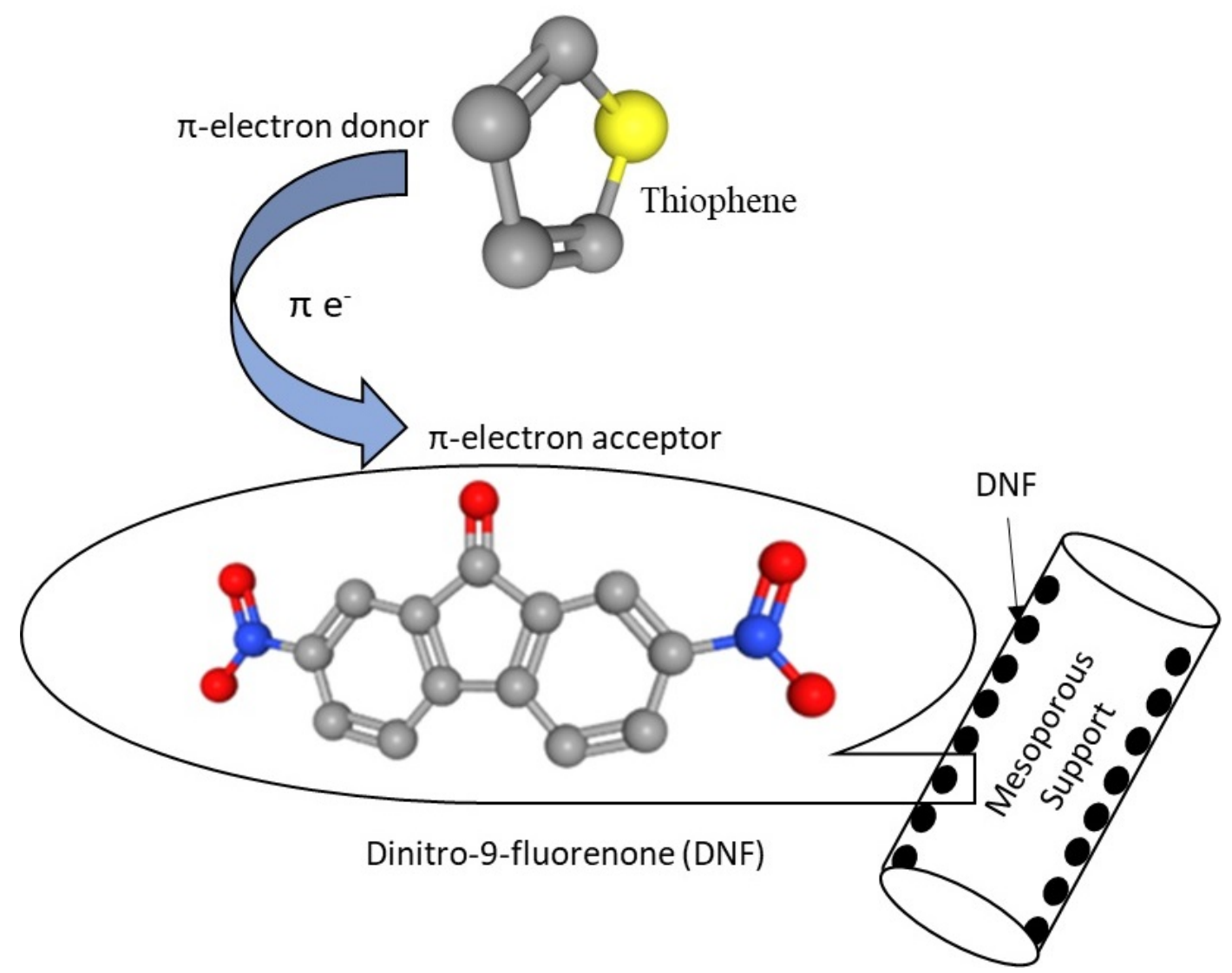

Figure 1. Mechanism of formation of electron-donor acceptor complex on CTC mesoporous adsorbent.

The effects of time, temperature, and adsorbent loadings on sulfur removal were determined by plotting a three-dimensional (3D) response surface and control graphs, as shown in Figure 2. Adsorbent A shows its highest adsorption activity with $76.3 \%$ of sulfur removal at an adsorbent loading of $20 \%$, $41{ }^{\circ} \mathrm{C}$ and a reaction time of $43 \mathrm{~min}$. However, at a temperature of $22^{\circ} \mathrm{C}$, an adsorbent loading of $30 \%$, and a reaction time of $27 \mathrm{~min}$, adsorbent $\mathrm{A}$ shows $74.0 \%$ sulfur removal. In terms of energy requirements, $\mathrm{ADS}$ at $41^{\circ} \mathrm{C}$ might not be ideal as compared to $22{ }^{\circ} \mathrm{C}$. Besides, raising the adsorption temperature by $20^{\circ} \mathrm{C}$ increased the sulfur removal only by $2 \mathrm{wt} . \%$. Adsorbent B showed a maximum sulfur removal of $57.2 \mathrm{wt} . \%$ at an adsorbent loading of $10 \%(0.25 \mathrm{~g})$, a temperature of $60{ }^{\circ} \mathrm{C}$ and an adsorption time of $27 \mathrm{~min}$. Similarly, adsorbent $C$ reached its maximum adsorption capacity at an adsorbent loading of $30 \%(0.75 \mathrm{~g})$, a temperature of $22{ }^{\circ} \mathrm{C}$ and an adsorption time of $27 \mathrm{~min}$, resulting a sulfur removal of $83 \mathrm{wt} . \%$. To fit the response function on sulfur removal, regression analysis was performed. The model equation for sulfur removal for adsorbents A, B, and C is shown in Table 3 . 
The individual effect of each of the process parameters, such as temperature $(\mathrm{X})$, time $(\mathrm{Y})$ and adsorbent loading $(Z)$, and combined effects of two of the process parameters on sulfur adsorption can be distinguished by using equations given in Table 3. For example, the interaction effects of $X-Y, X-Z$, and $\mathrm{Y}-\mathrm{Z}$ are not as significant as the individual effect of $\mathrm{X}, \mathrm{Y}$, and $\mathrm{Z}$ on the sulfur adsorption capacity of the adsorbent A. The typical steps of adsorption on a CTC adsorbent involve (i) external diffusion, which involves the transfer of sulfur compounds to the external surface of adsorbent due to the occurrence of a concentration gradient, (ii) internal diffusion of sulfur compounds into pores of the CTC adsorbent, and (iii) adsorption of sulfur compounds through interacting with 2,7-Dinitro-9-fluorenone ( $\pi$-acceptor) on the adsorbent. Although all are mesoporous materials, they differ in surface area, pore volume, and pore diameter [14]. Besides the number of active sites ( $\pi$-acceptor) on these adsorbents is also expected to differ from each other. Because of these structural differences, along with the change in the number of active sites, the optimum process parameters of adsorption were changed among CTC adsorbents.
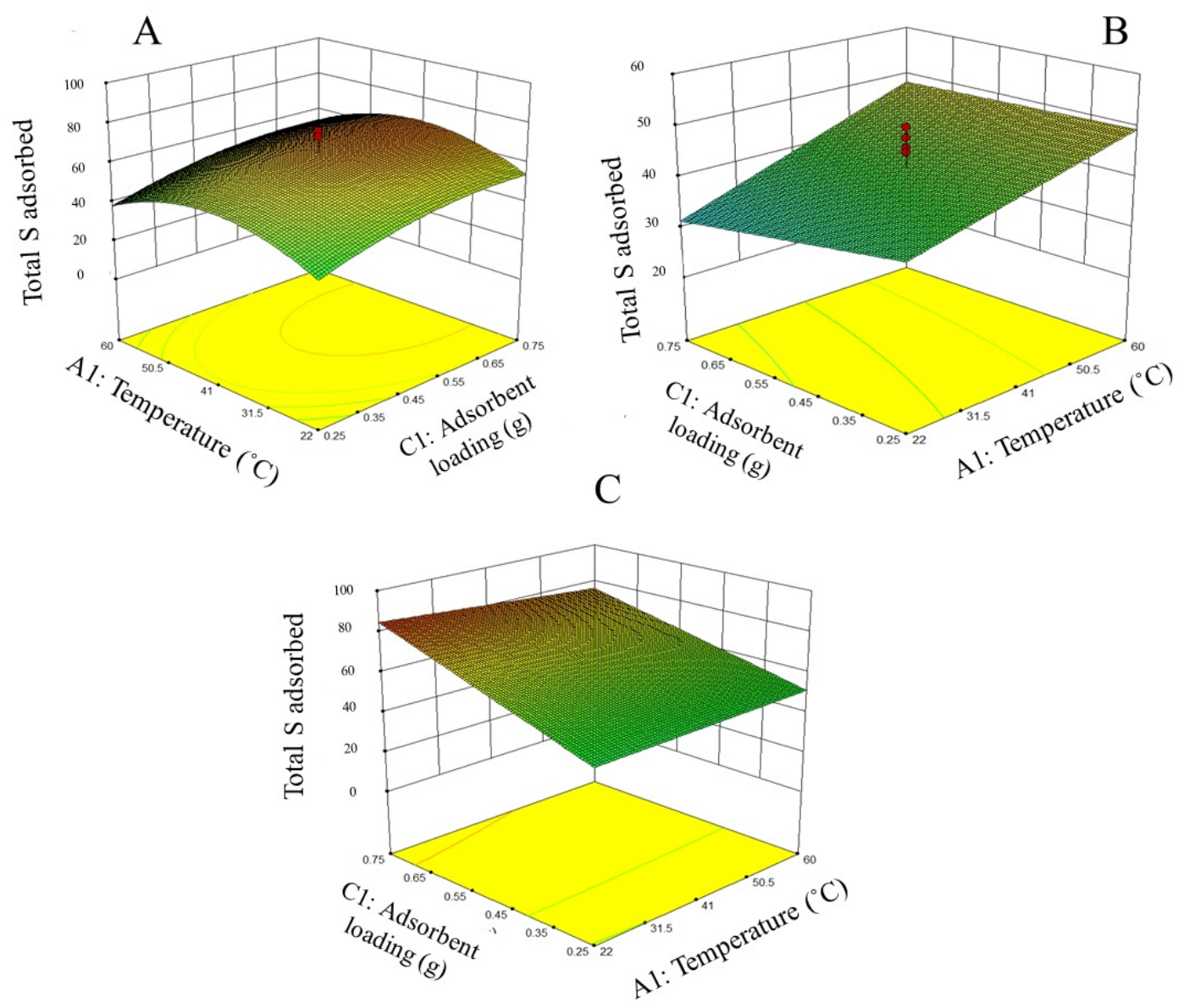

Figure 2. The three-dimensional response surfaces: Effects of temperature and adsorbent loading on desulfurization activity of adsorbents (A-C).

Table 3. Linear equations for adsorbents A, B, and C from Composite Design Expert based on the proposed set of experiments.

\begin{tabular}{cc}
\hline Adsorbent & Linear Equation \\
\hline $\mathrm{A}$ & Total S removal $=-5.37+0.17 \mathrm{X}+111.04 \mathrm{Y}+68.99 \mathrm{Z}-0.60 \mathrm{XY}-0.44 \mathrm{XZ}-75.31 \mathrm{YZ}$ \\
$\mathrm{B}$ & Total S removal $=50.73+0.34 \mathrm{X}-55.31 \mathrm{Y}-19.13 \mathrm{Z}+0.30 \mathrm{XY}-0.17 \mathrm{XZ}+48.46 \mathrm{YZ}$ \\
$\mathrm{C}$ & Total S removal $=103.46-0.01 \mathrm{X}-1.63 \mathrm{Y}-104.90 \mathrm{Z}-0.54 \mathrm{XY}+0.27 \mathrm{XZ}+116.77 \mathrm{YZ}$ \\
\hline
\end{tabular}

Note: Where $\mathrm{X}, \mathrm{Y}$, and $\mathrm{Z}$ are temperature $\left({ }^{\circ} \mathrm{C}\right)$, time (h), and adsorbent loading (wt. $\left.\%\right)$, respectively. 


\subsection{Kinetic Studies}

To analyze the kinetic data of adsorption experiments, two conventional kinetic models, such as pseudo-first, and pseudo-second-order models, were investigated [4,19]. Figure 3 shows the adsorption kinetic curves for the pseudo-first-order model of adsorbents A, B, and C for adsorptive desulfurization. The pseudo-first-order model formula is shown below:

$$
\ln \left(q_{e}-q_{t}\right)=\ln q_{e}-k_{1} * t
$$

where $\mathrm{q}_{\mathrm{e}}$ and $\mathrm{q}_{\mathrm{t}}$ are amounts of sulfur compounds adsorbed at equilibrium $\left(\mathrm{q}_{\mathrm{e}}\right)$ and at different times $\left(q_{t}\right)$ calculated in $\left(\mathrm{mg} \cdot \mathrm{g}^{-1}\right)$ and $\mathrm{k}_{1}$ is the pseudo-first-order model rate constant $\left(\mathrm{min}^{-1}\right)$. The values of $\mathrm{q}_{\mathrm{e}}$ and $\mathrm{k}_{1}$ can be determined from the intercept and slope of the linear plot of $\ln \left(\mathrm{q}_{\mathrm{e}}-\mathrm{q}_{\mathrm{t}}\right)$ versus $\mathrm{t}$. For the pseudo-first-order model, calculated values of $\mathrm{q}_{\mathrm{e}}$ and $\mathrm{k}_{1}$ are shown in Table 4, along with other kinetic parameters and correlation coefficients. The experimental data deviated considerably from the theoretical data. Moreover, the theoretical qe values found from the first-order kinetic model did not give reasonable values.

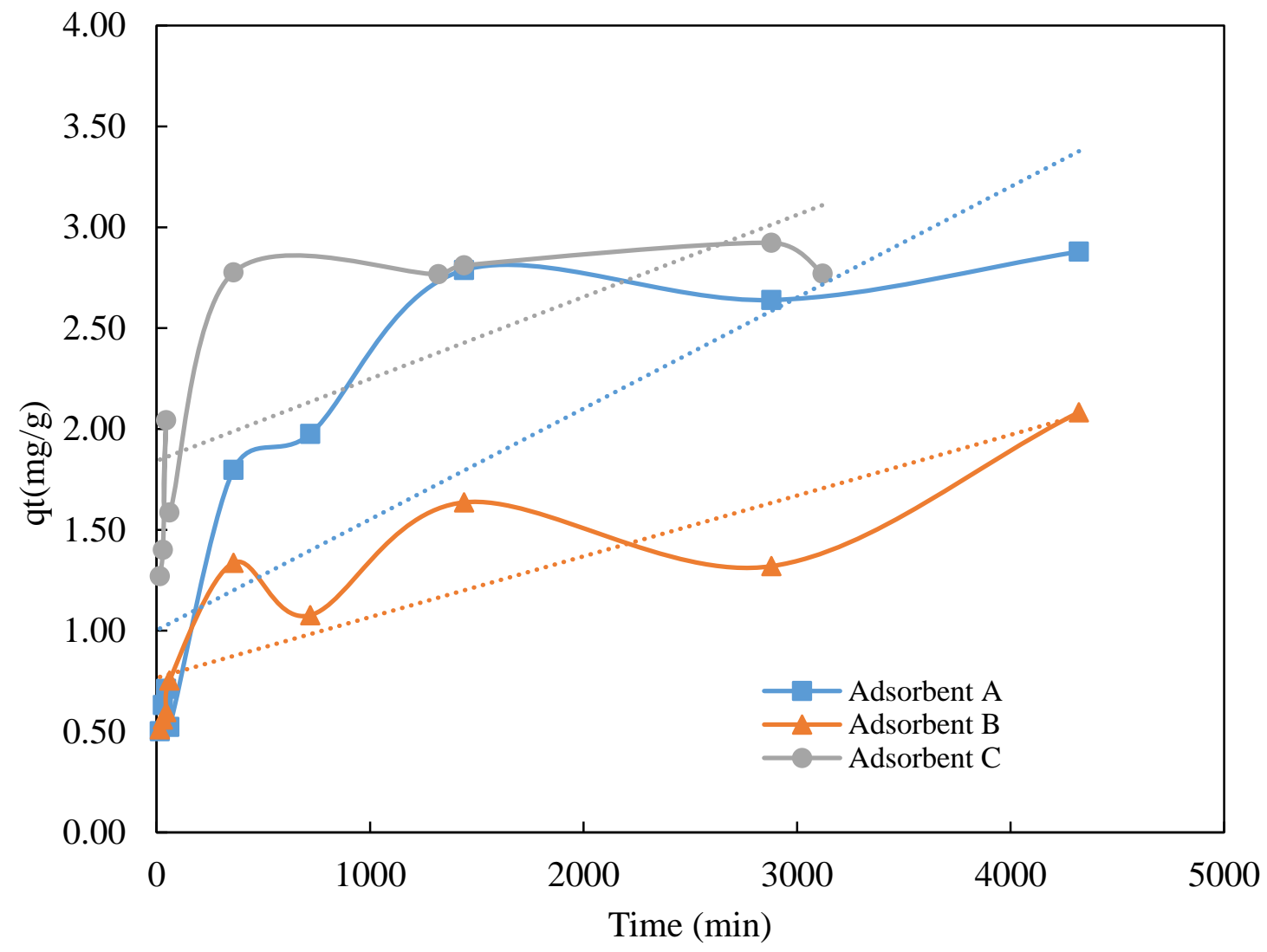

Figure 3. Pseudo first-order adsorption kinetics of adsorbents $\mathrm{A}, \mathrm{B}$, and $\mathrm{C}$. Temperature $=22{ }^{\circ} \mathrm{C}$, feed to adsorbent ratio $=5$. The solid line is the kinetic model, the dash line is pseudo first-order-model simulation.

Table 4. Kinetic parameters for pseudo-first and pseudo-second-order model.

\begin{tabular}{|c|c|c|c|c|c|c|c|}
\hline \multirow[b]{2}{*}{ Adsorbent } & \multirow{2}{*}{$\begin{array}{l}q_{e}(\exp ) \\
\left(m g \cdot g^{-1}\right)\end{array}$} & \multicolumn{3}{|c|}{ Pseudo-First Order Model } & \multicolumn{3}{|c|}{ Pseudo-Second Order Model } \\
\hline & & $\begin{array}{c}\mathrm{qe}_{\mathrm{e}}(\mathrm{cal}) \\
\left(\mathrm{mg} \cdot \mathrm{g}^{-1}\right)\end{array}$ & $\mathrm{K}_{1}\left(\min ^{-1}\right)$ & $\mathbf{R}^{2}$ & $\begin{array}{c}\mathrm{qe}_{\mathrm{e}}(\mathrm{cal}) \\
\left(\mathrm{mg} \cdot \mathrm{g}^{-1}\right)\end{array}$ & $\begin{array}{c}\mathrm{K}_{2} \\
\left(\mathrm{~g} \cdot \mathrm{mg}^{-1} \cdot \mathrm{min}^{-1}\right)\end{array}$ & $\mathbf{R}^{2}$ \\
\hline A & 2.79 & -0.00112 & $3.5 \times 10^{-4}$ & 0.39 & 1.01 & $1.59 \times 10^{-2}$ & 0.99 \\
\hline $\mathrm{B}$ & 2.08 & -0.00021 & $3.4 \times 10^{-5}$ & 0.18 & 1.20 & $1.22 \times 10^{-2}$ & 0.92 \\
\hline $\mathrm{C}$ & 2.78 & -0.00117 & $-9.0 \times 10^{-4}$ & 0.33 & 1.03 & $9.21 \times 10^{-3}$ & 0.99 \\
\hline
\end{tabular}


The kinetic parameters of the pseudo-second-order model are also presented in Table 4. From the table, it can be seen that the pseudo-second-order model given in Equation (8) adequately fits the adsorption experimental data for all three adsorbents.

$$
\frac{t}{q_{t}}=\frac{1}{k_{2} q_{e}^{2}}+\frac{t}{q_{e}}
$$

This observation was corroborated by the correlation coefficient $R^{2}$ values obtained from this model. For adsorbents $\mathrm{A}$ and $\mathrm{C}$, the $\mathrm{R}^{2}$ values were higher than its counterpart, however, the pseudo-first-order model did not show $\mathrm{R}^{2}$ higher than 0.5 . However, with the pseudo-second-order model, both adsorbents $A$ and $C$ showed $\mathrm{R}^{2}$ values greater than 0.99 , suggesting a better correlation of the experimental data to the kinetic model, as depicted in Figure 4.

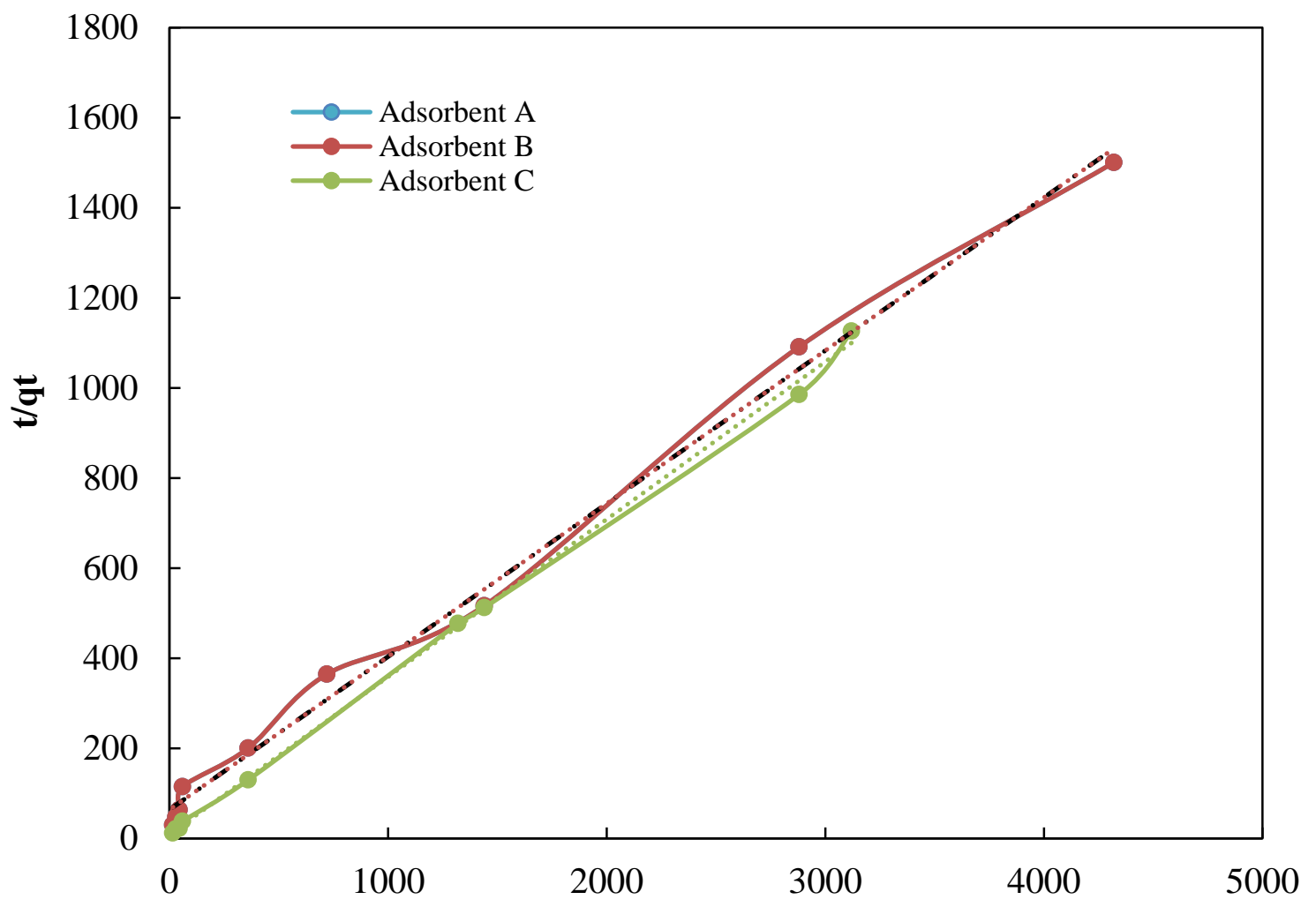

Time (min)

Figure 4. Pseudo-second order adsorption kinetics of adsorbents $\mathrm{A}, \mathrm{B}$, and $\mathrm{C}$ at $22^{\circ} \mathrm{C}$ using $1: 5$ adsorbent to feed ratio. The solid line is the results for the kinetic model, the dashed line is a pseudo-second order model simulation.

The comparatively inferior performance of adsorbent B can also be observed from the kinetic studies. As reported in our earlier study [14], adsorbent B was inferior in textural properties that are critical to be a desirable adsorbent for adsorption [20-22]. Furthermore, this poor performance was also observed in consecutive parameter optimization experiments. Due to the inferior performance of adsorbent $B$, thermodynamic and regeneration studies were only carried out for adsorbents A and C.

\subsection{Adsorption Thermodynamic}

As part of this study, the activation energy $\left(\mathrm{E}_{\mathrm{a}}\right)$ was calculated to get an insight into adsorption mechanisms. Using the Arrhenius equation, the activation energies were calculated for adsorbents A 
and $C$ in the temperature range of 295-314 K. The activation energy values of 8.27 and $8.29 \mathrm{~kJ} \cdot \mathrm{mol}^{-1}$ were calculated by plotting $\ln \mathrm{k}_{2}$ vs. $1 / \mathrm{T}$ for adsorbents $\mathrm{A}$ and $\mathrm{C}$ (Figure 5). It is known that lower activation energies $\left(E_{a}\right)$ in the range of 5 to $40 \mathrm{~kJ} \cdot \mathrm{mol}^{-1}$ correspond to physical adsorption, while higher activation energies (40-800 kJ.mol ${ }^{-1}$ ) correspond to chemical adsorption [23]. The calculated activation energy values for adsorbents $A$ and $C$ shown in Table 5 suggest that sulfur compounds removal from the model fuel proceeded via the physical adsorption pathway. This means that the adsorption process is not associated with chemical reactions, instead, sulfur molecules are attracted to the adsorbent via the weak van der Waals forces or hydrogen bonding [4].

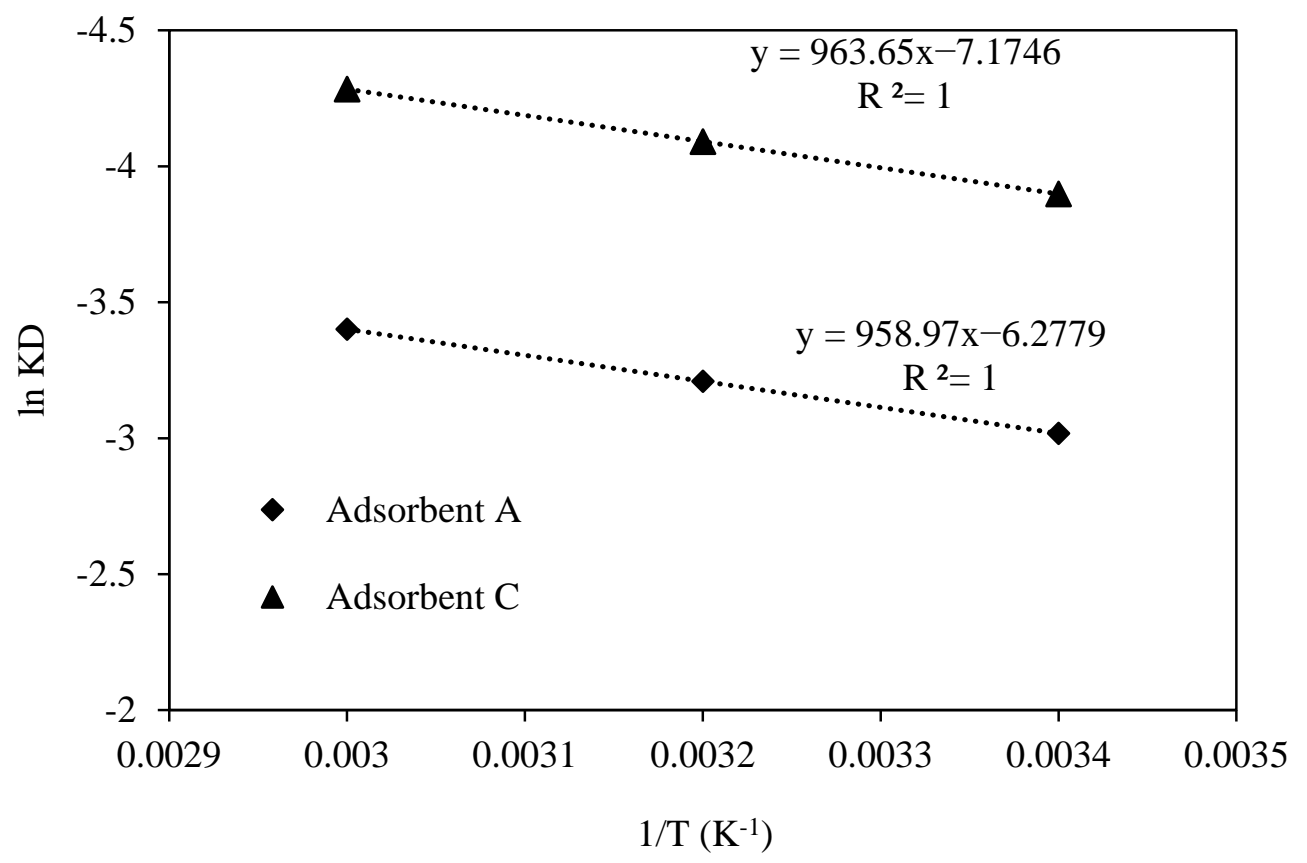

Figure 5. The activation energy $\left(E_{a}\right)$ plot for adsorbents $A$ and $C$.

Table 5. Activation energy calculated values for adsorbents A and C.

\begin{tabular}{cccc}
\hline Adsorbent & Activation Energy (Ea) (kJ/mol) & $\boldsymbol{\Delta} \mathbf{H ~ ( k J / m o l )}$ & $\boldsymbol{\Delta} \mathbf{S ~ ( J / m o l ~ K )}$ \\
\hline A & 8.27 & 15.5 & -85.2 \\
C & 8.29 & 15.3 & -77.1 \\
\hline
\end{tabular}

The free activation energy $\left(\Delta \mathrm{G}^{0}\right)$, enthalpy $\left(\Delta \mathrm{H}^{0}\right)$, and entropy $\left(\Delta \mathrm{S}^{0}\right)$ are usually involved in an adsorption process. To evaluate if the adsorption process of an adsorbate is spontaneous or not, the above-mentioned parameters have to be determined. As presented in Table 6, the free activation energy $\left(\Delta \mathrm{G}^{0}\right)$ values at $295 \mathrm{~K}$ were found to be 9.6 and $7.5 \mathrm{~kJ} \cdot \mathrm{mol}^{-1}$ for adsorbents $A$ and $C$, respectively. At $318 \mathrm{~K}$, these values were 10.1 and $7.9 \mathrm{~kJ} \cdot \mathrm{mol}^{-1}$. At $333 \mathrm{~K}$ these values were 10.6 and $8.4 \mathrm{~kJ} \cdot \mathrm{mol}^{-1}$. The positive values of $\Delta \mathrm{G}^{0}$ mean that adsorption of sulfur compounds on adsorbents $\mathrm{A}$ and $\mathrm{C}$ is a slow process [24]. Using $\ln K_{D}$ vs. $1 / T$ values, (Figure not shown), enthalpy and entropy values were calculated using the intercept and slope.

Table 6. Free activation energy $(\Delta \mathrm{G})$ values for adsorbents $\mathrm{A}$ and $\mathrm{C}$.

\begin{tabular}{ccc}
\hline \multirow{2}{*}{ Temperature (K) } & \multicolumn{2}{c}{$\Delta \mathrm{G} \mathrm{(kJ/mol)}$} \\
\cline { 2 - 3 } & Adsorbent A & Adsorbent C \\
\hline 295 & 9.62 & 7.45 \\
318 & 10.08 & 7.94 \\
333 & 10.56 & 8.37 \\
\hline
\end{tabular}


As given in Table 5, the adsorption enthalpies $\left(\Delta \mathrm{H}^{0}\right)$ with adsorbents $\mathrm{A}$ and $\mathrm{C}$ were calculated to be 15.5 and $15.3 \mathrm{~kJ} \cdot \mathrm{mol}^{-1}$, respectively. The positive values of $\Delta \mathrm{H}^{0}$ indicate that the adsorption process is endothermic [25]. The change of entropy $\left(\Delta S^{0}\right)$ values in the adsorption system were -85.2 and $-77.1 \mathrm{~J} \cdot \mathrm{mol}^{-1} \mathrm{~K}^{-1}$ for adsorbents $\mathrm{A}$ and $\mathrm{C}$, respectively. The negative entropy values among adsorbents $\mathrm{A}$ and $\mathrm{C}$ indicate that the internal structure of these adsorbents hardly changes during the adsorption process [26].

\section{Regeneration and Reusability}

The spent adsorbent was regenerated by solvent washing with chloroform, dichloromethane, and carbon tetrachloride. These solvents were used since they are polar and suitable for the extraction of polar organosulfur compounds. Since these solvents have lower boiling points than sulfur compounds present in the petroleum feedstocks, they were completely removed from the extract solution by a rotary evaporator, and concentrated extracts were analyzed for their sulfur levels. The sulfur extraction efficiencies of chloroform, carbon tetrachloride, and dichloromethane with adsorbent $\mathrm{C}$ are shown in Figure 6. The highest sulfur removal was achieved using dichloromethane. It removed $80 \%$ of sulfur molecules that were adsorbed on the adsorbent $C$. The reusability of adsorbent $C$ was studied three times. After each run, the spent adsorbent was regenerated by solvent washing with DCM. The residual solvent molecules on the adsorbent were removed by drying at $100{ }^{\circ} \mathrm{C}$. The results are shown in Figure 7 . The fresh adsorbent showed $83.8 \%$ sulfur removal. After the first regeneration, the sulfur removal efficiency dropped by only $7 \%$. A significant drop was noted when the adsorbent $C$ was reused for the third time. The nitrogen analysis of the solvent extract was carried out to determine the leaching of the immobilized EDA linker and $\pi$-acceptor during regeneration with DCM. The solvent extract of first and second regeneration contained 36 and $193 \mathrm{ppm}$ of nitrogen, respectively, due to leaching of EDA and DNF. The leaching of DNF from the adsorbent $C$ caused the drop in the number of available adsorption sites and thus its adsorption capacity after successive regenerations.

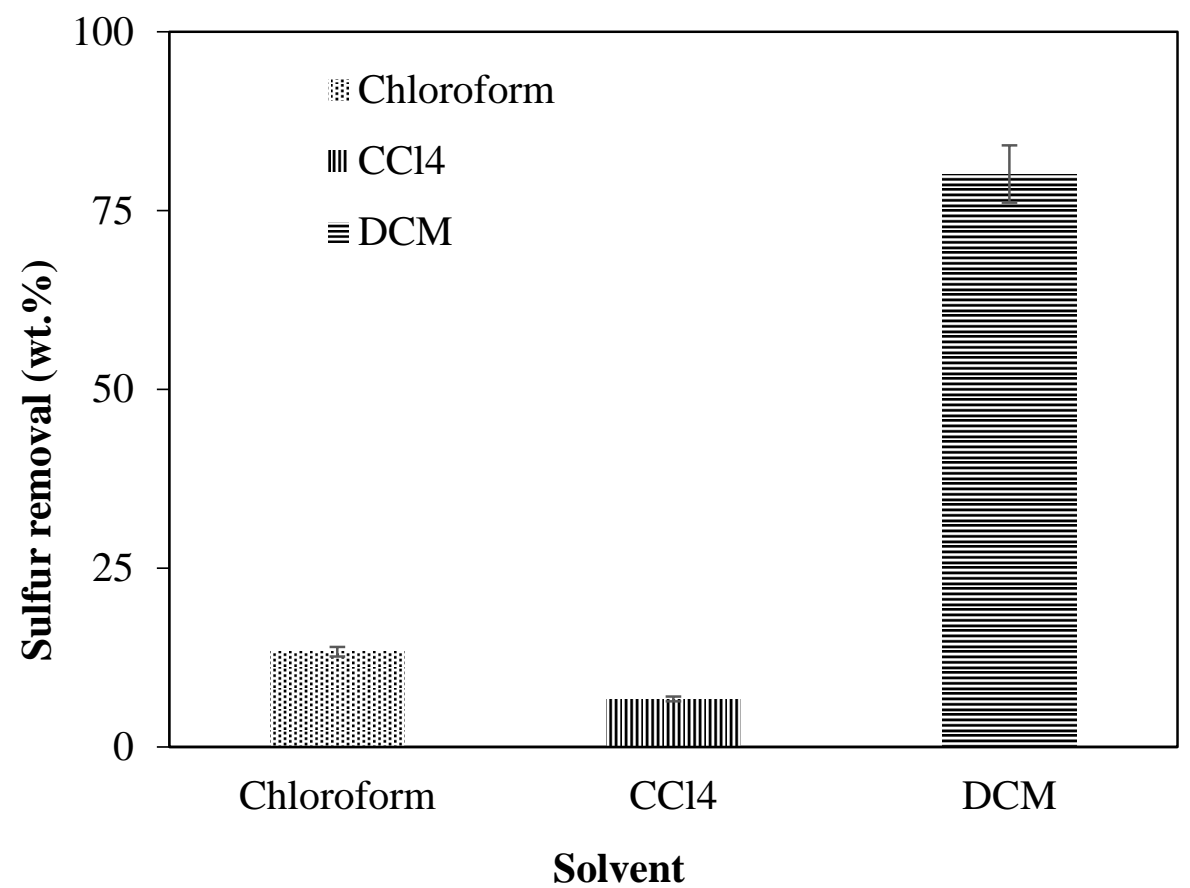

Figure 6. Sulfur removal from the spent adsorbent $C$ after $8 \mathrm{~h}$ of regeneration with chloroform, carbon tetrachloride, and dichloromethane. 


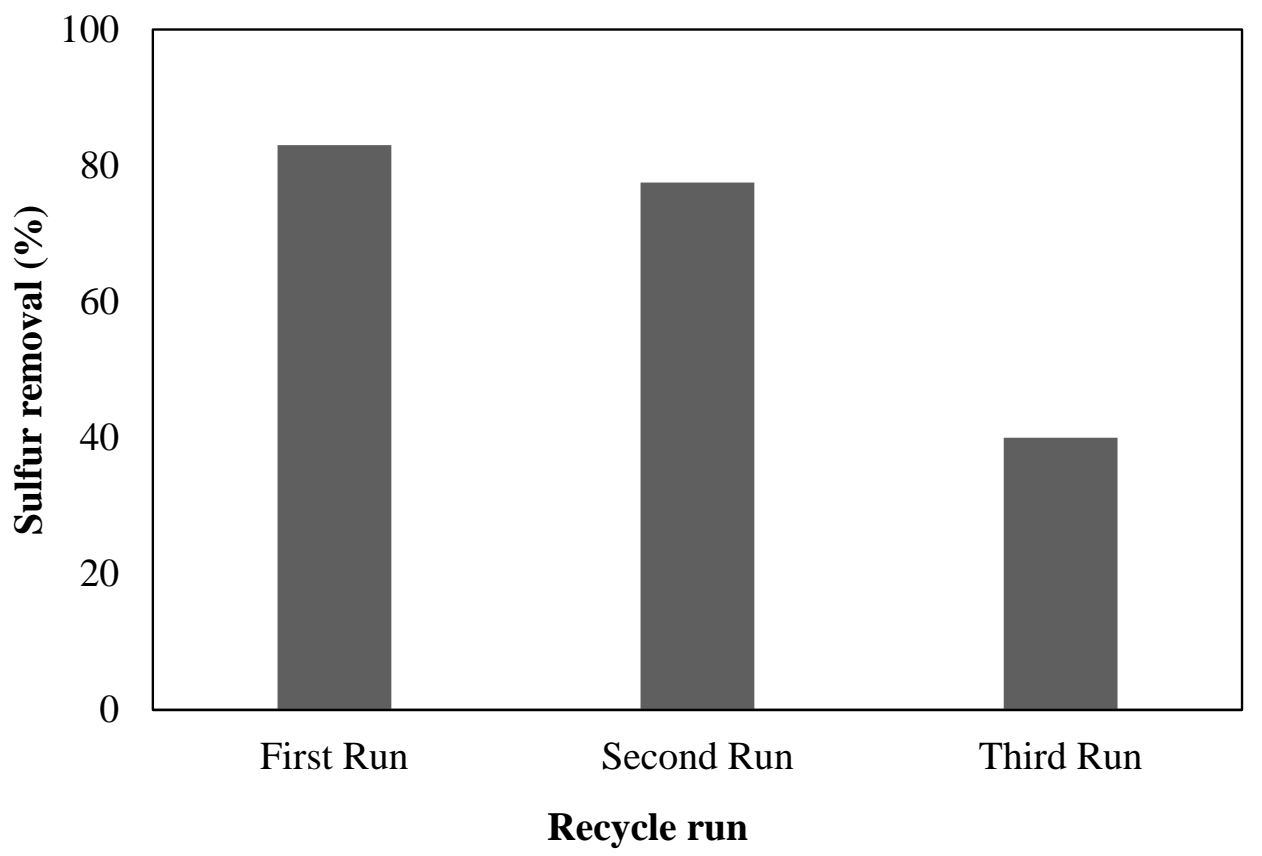

Figure 7. Reusability of adsorbent $\mathrm{C}$ after regeneration with dichloromethane.

\section{Conclusions}

In this study, optimization, regeneration, and kinetic evaluations were carried out for three CTC adsorbents for adsorptive desulfurization of a model feed. The parameter optimization study showed optimum adsorption at ambient conditions. Adsorbent $C$ had the highest sulfur removal capacity in a shorter period. The pseudo-second-order model had the best fit with the kinetic data of all three adsorbents. The activation energy $\left(\mathrm{E}_{\mathrm{a}}\right)$ values indicated physical adsorption of sulfur compounds on adsorbents $\mathrm{A}$ and $\mathrm{C}$. The values of free activation energy and enthalpy suggested that the adsorption of sulfur compounds on adsorbents $A$ and $C$ is a slow endothermic process. Entropy values evidenced that adsorbent $\mathrm{A}$ and $\mathrm{C}$ experienced no significant change in the internal structure during adsorption of sulfur compounds. The results of regeneration showed that dichloromethane is an effective solvent for regeneration, and the adsorbent $C$ can be used at least two times.

Author Contributions: Conceptualization, A.B.-d.1.C. and S.V.; methodology, A.B.-d.1.C.; and S.V.; software, A.B.-d.1.C.; validation, P.E.B., S.V., J.A. and A.K.D.; formal analysis, A.B.-d.l.C.; investigation, A.B.-d.l.C.; resources, A.K.D.; data curation, A.B.-d.l.C.; writing-original draft preparation, A.B.-d.l.C. and S.V.; writing-review and editing, S.V., A.K.D. and P.E.B.; supervision, A.K.D. and J.A.; All authors have read and agreed to the published version of the manuscript.

Funding: This research received no external funding.

Acknowledgments: The authors thank the Natural Sciences and Engineering Research Council of Canada (NSERC), and the Canada Research Chair Program for funding the project.

Conflicts of Interest: The authors declare no conflict of interest.

\section{References}

1. Srivastava, V.C. An evaluation of desulfurization technologies for sulfur removal from liquid fuels. RSC Adv. 2012, 2, 759-783. [CrossRef]

2. Choi, K.-H.; Kunisada, N.; Korai, Y.; Mochida, I.; Nakano, K. Facile ultra-deep desulfurization of gas oil through two-stage or -layer catalyst bed. Catal. Today 2003, 86, 277-286. [CrossRef]

3. Da Costa, P.; Manoli, J.-M.; Potvin, C.; Djéga-Mariadassou, G. Deep HDS on doped molybdenum carbides: From probe molecules to real feedstocks. Catal. Today 2005, 107, 520-530. [CrossRef]

4. Duan, F.; Chen, C.; Wang, G.; Yang, Y.; Liu, X.; Qin, Y. Efficient adsorptive removal of dibenzothiophene by graphene oxide-based surface molecularly imprinted polymer. RSC Adv. 2014, 4, 1469-1475. [CrossRef] 
5. Jafarinejad, S. Control and treatment of sulfur compounds specially sulfur oxides (SOx) emissions from the petroleum industry: A review. Chem. Int. 2016, 2, 242-253.

6. Song, C. An overview of new approaches to deep desulfurization for ultra-clean gasoline, diesel fuel and jet fuel. Catal. Today 2003, 86, 211-263. [CrossRef]

7. Ania, C.O.; Bandosz, T.J. Importance of Structural and Chemical Heterogeneity of Activated Carbon Surfaces for Adsorption of Dibenzothiophene. Langmuir 2005, 21, 7752-7759. [CrossRef]

8. Misra, P.; Badoga, S.; Dalai, A.K.; Adjaye, J. Enhancement of sulfur and nitrogen removal from heavy gas oil by using polymeric adsorbent followed by hydrotreatment. Fuel 2018, 226, 127-136. [CrossRef]

9. Santos, A.L.; Reis, R.A.; Rossa, V.; Reis, M.M.; Costa, A.L.H.; Veloso, C.D.O.; Henriques, C.A.; Zotin, F.M.; Paredes, M.L.; Silveira, E.B.; et al. Silica-alumina impregnated with cerium, nickel, and molybdenum oxides for adsorption of sulfur and nitrogen compounds from diesel. Mater. Lett. 2012, 83, 158-160. [CrossRef]

10. Velu, S.; Song, C.; Fuels, C.; Program, C.; Engineering, G. Zeolite-based adsorbents for Desulfurization of Jet fuel by Selective Adsorption. Fuel Chem. 2002, 47, 447-448.

11. Yitzhaki, D.; Landau, M.; Berger, D.; Herskowitz, M. Deep desulfurization of heavy atmospheric gas oil with CoMoAl catalysts effect of sulfur adsorption. Appl. Catal. A Gen. 1995, 122, 99-110. [CrossRef]

12. Lee, S.-W.; Ryu, J.W.; Min, W. SK Hydrodesulfurization (HDS) Pretreatment Technology for Ultralow Sulfur Diesel (ULSD) Production. Catal. Surv. Asia 2003, 7, 271-279. [CrossRef]

13. Hendricks, D.W. Water Treatment Unit Processes: Physical and Chemical; CRC Press: Boca Raton, FL, USA, 2006.

14. De La Cruz, A.B.; Boahene, P.; Vedachalam, S.; Dalai, A.; Adjaye, J. Adsorptive desulfurization through charge-transfer complex using mesoporous adsorbents. Fuel 2020, 269, 117379. [CrossRef]

15. Laidler, K.J. The development of the Arrhenius equation. J. Chem. Educ. 1984, 61, 494-498. [CrossRef]

16. Field, J.A.; Sierra-Alvarez, R. Biodegradability of chlorinated solvents and related chlorinated aliphatic compounds. Rev. Environ. Sci. Bio Technol. 2004, 3, 185-254. [CrossRef]

17. Crowson, R.; Hargrove, D.; Pout, C.R. Chlorine regeneration of platinum group metal zeolite catalysts. U.S. Patent 3,986,982, 19 October 1976.

18. Okawa, K.; Suzuki, K.; Takeshita, T.; Nakano, K. Regeneration of granular activated carbon with adsorbed trichloroethylene using wet peroxide oxidation. Water Res. 2007, 41, 1045-1051. [CrossRef]

19. Wang, X.; Zhang, Y.; Luo, W.; Elzatahry, A.A.; Cheng, X.; Alghamdi, A.; Abdullah, A.M.; Deng, Y.; Zhao, D. Synthesis of Ordered Mesoporous Silica with Tunable Morphologies and Pore Sizes via a Nonpolar Solvent-Assisted Stöber Method. Chem. Mater. 2016, 28, 2356-2362. [CrossRef]

20. Almarri, M.; Ma, X.; Song, C. Selective Adsorption for Removal of Nitrogen Compounds from Liquid Hydrocarbon Streams over Carbon- and Alumina-Based Adsorbents. Ind. Eng. Chem. Res. 2009, 48, 951-960. [CrossRef]

21. Anirudhan, T.; Radhakrishnan, P. Thermodynamics and kinetics of adsorption of $\mathrm{Cu}$ (II) from aqueous solutions onto a new cation exchanger derived from tamarind fruit shell. J. Chem. Thermodyn. 2008, 40, 702-709. [CrossRef]

22. Saadi, R.; Saadi, Z.; Fazaeli, R.; Fard, N.E. Monolayer and multilayer adsorption isotherm models for sorption from aqueous media. Korean J. Chem. Eng. 2015, 32, 787-799. [CrossRef]

23. Fei, L.; Rui, J.; Wang, R.; Lu, Y.; Yang, X. Equilibrium and kinetic studies on the adsorption of thiophene and benzothiophene onto NiCeY zeolites. RSC Adv. 2017, 7, 23011-23020. [CrossRef]

24. Zhang, Y.; Yu, F.; Cheng, W.; Wang, J.; Ma, J. Adsorption Equilibrium and Kinetics of the Removal of Ammoniacal Nitrogen by Zeolite X/Activated Carbon Composite Synthesized from Elutrilithe. J. Chem. 2017, 2017, 1-9. [CrossRef]

25. Foo, K.; Hameed, B. Insights into the modeling of adsorption isotherm systems. Chem. Eng. J. 2010, 156, 2-10. [CrossRef]

26. Whalen, J.W. Physical chemistry of surfaces, fourth edition (Adamson, Arthur W.). J. Chem. Educ. 1983, 60, A322. [CrossRef]

Publisher's Note: MDPI stays neutral with regard to jurisdictional claims in published maps and institutional affiliations.

(C) 2020 by the authors. Licensee MDPI, Basel, Switzerland. This article is an open access article distributed under the terms and conditions of the Creative Commons Attribution (CC BY) license (http://creativecommons.org/licenses/by/4.0/). 